\title{
Comparative Study on the In-Ladle Treatment Techniques for Nodulizing the Iron's Graphite
}

\author{
Imre Kiss
}

\begin{abstract}
The objectives of this research is to study and understand the nodulizing of ductile iron using in-ladle treatment process. Among the more common nodulizing agents is magnesium (Mg) which is conventionally added to the cast iron by combining suitable alloys of one or both of these elements with molten cast iron. Depending on the characteristics of each master alloy used as nodulizer, different treatment methods and techniques are used, among these, the most widely used being in-ladle, in-mould, and flow-through, the first being the most used. This research deals with the parameters, that affect the quality of ductile iron produced using in-ladle treatment process. The parameters involved are the percentage of magnesium-ferrosilicon ( $\mathrm{Fe}-\mathrm{Si}-\mathrm{Mg}$ ) used and the nodulizing technique. In-ladle treatment used consists of a deep pocket into the bottom of ladle, in which magnesium-ferrosilicon is placed into it together with a steel scrap barrier (steel sheets) or calcium carbide. This study, take into account, the degree of assimilation of magnesium, which shows the performance of the chosen process, depending on the nodulizer used and the temperature of the treatment.
\end{abstract}

Keywords: assimilation degrees of magnesium; ductile iron (nodular graphite iron); in-ladle treatment methods; magnesium; nodulizing agents; silicon-based master alloys

\section{INTRODUCTION}

Ductile iron (nodular graphite iron) has became one of the most important engineering materials, in view of its excellent castability, significantly better mechanical properties and low cost [1-6]. Generally, ductile cast iron consist of graphite spheroids dispersed in a matrix. The ductile iron can be produced by adding small quantities of magnesium $[\mathrm{Mg}]$ to a base cast iron which transforms graphite spheroids instead of flakes [3-13]. Therefore, production of nodular cast iron consists of three basic stages [1-13]:

- Casting of basic cast iron with proper chemical composition, characterised by the high graphitization (nodulizing) ability. This is insured by appropriate high content of carbon and silicon. The cast iron cannot contain elements opposing the crystallization of nodular graphite (the antispheroidizing elements) in amounts exceeding the determined limits;

- Introducing the spheroidizing (nodulizing) agent into the molten metal, most often magnesium or its carriers in the form of various alloys being used for this purpose;

- Subjecting the cast iron to graphitizing (nodulizing), modification directly after the spheroidizing (nodulizing), with ferrosilicon or calcium silicon with small additions of other elements.

The carbon present in molten iron is normally in flake form, and if the metal solidifies with the carbon in such form [1-3]. For a number of years it has been known that flake graphite can be converted to the nodular form by the use of nodulizing agents, which initially were used to treat gray iron as it flowed from the melting furnance or when it was received in the ladle from which castings were poured $[1,4]$.

Nodulization is a process of controlling the structure and properties by changing the graphite shape from flakes to spheroidal in cast iron during solidification [1-8]. The nodularisers are added in liquid iron to promote the formation of spheroidal or compacted form of graphite, specific for the ductile irons. Therefore, a certain quantity of magnesium is necessary to obtain the graphite in spheroidal or compacted form [1-13].

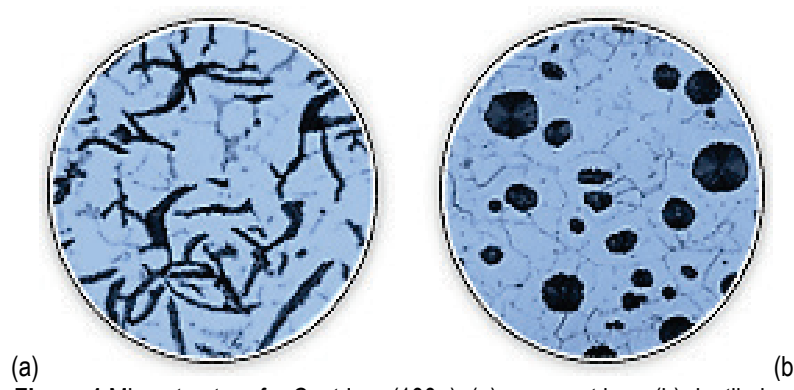

Figure 1 Microstructure for Cast Iron (100x): (a) gray cast iron; (b) ductile iron

The properties of cast iron can be improved by the addition to it of nodulizing elements, commonly magnesium and cerium, or both [1-13]. In the presence of these elements the free graphite in cast iron tends to assume a spheroidal form, and both the tensile strength and ductility of the cast iron are increased. Nodulizing agents containing the nodulizing elements are added, suitably, by immersing them into the molten iron. Among the nodulizing agents which are immersed into iron are magnesium-ferrosilicon and ceriumcontaining magnesium-ferrosilicon $[1,3,8,11]$.

Nodularizing, or magnesium treatment, of cast iron is a method of modifying the solidification structure so that the graphite phase precipitates and grows as spherical particles instead of flakes, thus resulting in a ductile cast iron with significantly improved mechanical properties [1-13]. The nodularizing action can be described as desulfurizing and deoxidizing treatment, where elements having strong affinity to both sulfur and oxygen are added. This is done by adding a strong sulfide and oxide forming agents as magnesium. The less violent treatment will, for the best available processes, give low fume, smoke and slag formations, and consequently high magnesium recoveries [1, 4].

According to the prior art nodular cast iron may be produced by treating the molten cast iron with nodulizing agent so as to impart to the cast iron in the as-cast condition a minimum amount of the nodulizing agent [1-6]. Among the 
more common nodulizing agents is magnesium which is conventionally added to the cast iron by combining suitable alloys of one or both of these elements with molten cast iron.

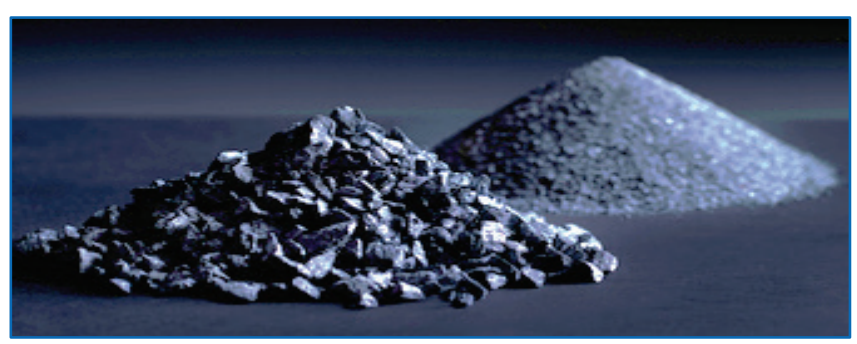

Figure 2 Silicon-based (light) pre-alloys used as nodulizer

The most commonly used as nodulizers are siliconbased light pre-alloys which contains spheroidal graphite forming elements such as magnesium, cerium, calcium, barium, etc. On the other hand, silicon which is the primary graphitising element, prevents carbide formation and controls the release of magnesium. Nodularisers are ferrosilicon alloys containing magnesium with, when needed, rare-earth elements [1-6]. In practice, the nodulariser usually contain magnesium, as pure magnesium, or as an alloy, such as magnesium-ferro-silicon ( $\mathrm{Fe}-\mathrm{Si}-\mathrm{Mg}$ alloy) or nickel-magnesium ( $\mathrm{Ni}-\mathrm{Mg}$ alloy), which may contain rare earth metals (cerium, lantan), required in order to counteract the harmful effect of certain trace elements on the iron graphite shape (notably lead, antimony and bismuth). Magnesium is the main element in $\mathrm{Fe}-\mathrm{Si}-\mathrm{Mg}$ alloys responsible for creating the necessary conditions for the graphite phase to grow from the liquid into the required spheroidal form $[1,2]$. The level of magnesium can be selected from a range between 5 to $10 \%$ [1-6]. For commercial production of ductile iron, these master alloys may contain additions of aluminum, calcium, or rare earths (cerium, lantan). Calcium is an element which retards the rate of reaction of magnesium with the liquid iron and thereby improves magnesium recovery and reduces the reaction's violence. In excessive amounts, Calcium $[\mathrm{Ca}]$ can produce slag $[1,2]$.

Nowadays, iron foundries supply varieties of ductile iron products, ranging from low quality to high quality. Several choice factors include treatment method used, degree of acceptable reactivity and economy of addition rate [4-13]. Many ways of introducing magnesium or magnesium containing master alloys into cast iron have been developed. Light master alloys require the use of appropriate methods for improving magnesium recovery by keeping the treatment alloy below the liquid iron surface until it is fully dissolved, thus minimizing magnesium losses and reducing pyroeffect $[1,12]$. The decision of whether to use a nodulariser containing rare earth elements is generally determined by the quality and consistency of the raw materials used as melt stock. Depending on the characteristics of each master alloy used as nodulizer, different treatment methods and techniques are used, among these, the most widely used being in-ladle, in-mould, and flow-through, the first being the most used $[1,4,7,11,12]$.

\section{IN-LADLE TREATMENT METHODS}

In-ladle nodulizing is one of the most common treatment technology used in today industries due to its simplicity [1$7,12]$. For in-ladle treatment, the magnesium-ferrosilicon is introduced into a pocket built into the ladle and is then covered with either steel punching or ferrosilicon. The cover acts as a physical barrier between the magnesiumferrosilicon and the pouring molten cast iron which delays reaction time, prevents floating of magnesium-ferrosilicon $[1,13]$.

A number of in-ladle treatment techniques have been developed to prepare ductile iron over the years $[1,4,12]$. The most common treatment techniques in use today are the plunging process, the open ladle process, the sandwich process, and tundish process.

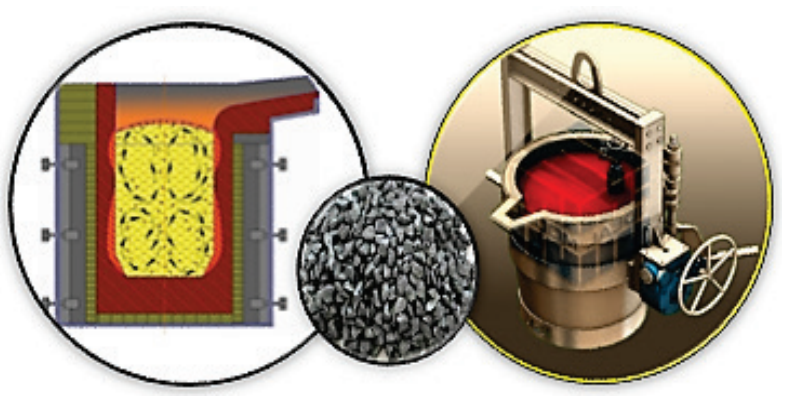

Figure 3 In-ladle treatment

As a way of increasing the assimilation of magnesium $(\mathrm{Mg})$ from the pre-alloy, in order to achieve the nodularization of the graphite of cast iron, changes made constructively to the treatment ladle were used $[1,12,13]$. Thus have evolved the treatment procedures, from simply immersion with the plunging bell, to the treatment in a special pocket made in the bottom of the treatment ladle [1, $12,13]$.

- The Plunging process (Fig. 4) is one of the most widely used for ductile iron production, which use a refractory plunger bell, containing pure magnesium or magnesium master alloys. This method is simple and widely used but magnesium recovery rates are inconsistent $[1,4,9,12]$. Moreover it is necessary to use more nodulariser to successfully achieve the required level of treatment.

- The Open Ladle process (Fig. 5) is the choice of many foundries worldwide, due to simplicity and low investment costs $[1,4,9,12]$. The nodulariser is added into the bottom of treatment ladle and the ladle is subsequently filled. The disadvantages of the process are excessive flame coupled with variable magnesium recoveries and inefficient use of the treatment alloy.

- The Sandwich (Overpouring) process (Fig. 6) is an improved modification of the open ladle process. In this process, the magnesium-ferrosilicon is introduced into pocket built into the ladle and is covered with steel scrap or ferrosilicon $[1,4,9,12]$. The iron is then poured into the ladle and reaction with the treatment alloy is slowed by the steel scrap barrier (steel sheets). The major advantages of this method are simplicity and low cost. 
The sandwich process is flexible and can be used for different sizes of ladles.

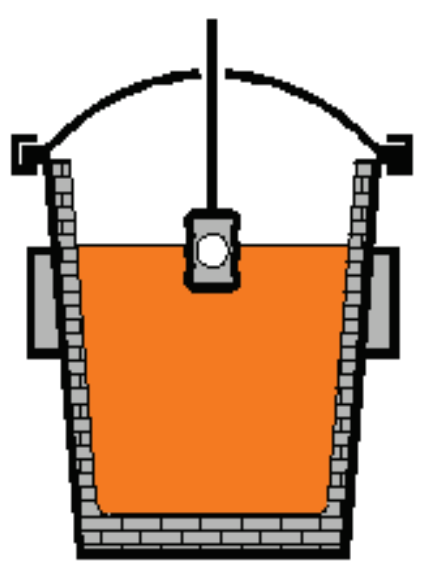

Figure 4 The Plunging process

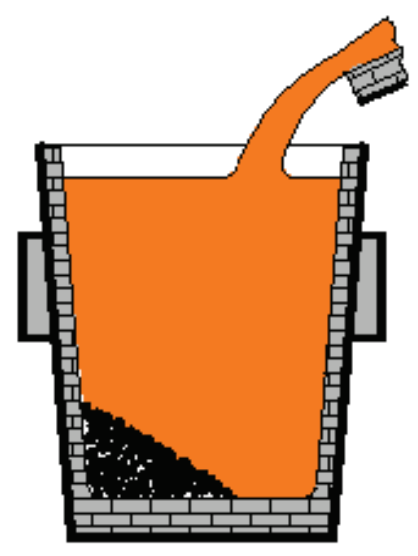

Figure 5 The Open Ladle process

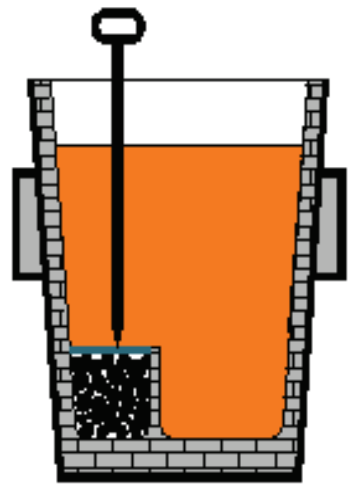

Figure 6 The Sandwich process
- The Trigger method (Fig. 7) is similar to the Sandwich method and uses the same treatment ladle with a "pocket", in which the nodulizer is placed, over which a layer of calcium carbide is placed, instead of steel sheets. The liquid iron causes a layer of slag over the nodulizing alloy, which prevents, for the time being, direct contact between cast iron and the nodulizer [1, 4, 9, 12]. After filling the treatment ladle, the slag layer is perforated with a steel bar, thus making contact between the iron and the nodulizer. The reaction is less violent.

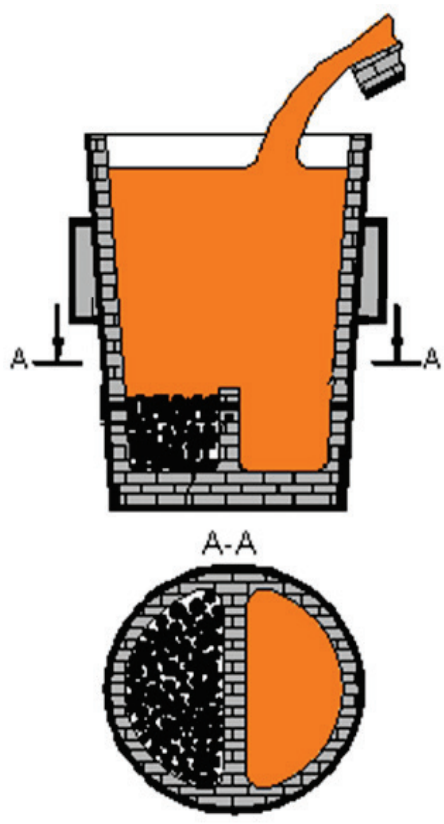

Figure 7 The Trigger method

- The Tundish-Cover process (Fig. 8) is a further improvement of sandwich method and is aimed at reducing the oxygen level inside the ladle by applying a special cover $[1,4,9,12]$. A special dividing wall is located at the bottom of the treatment ladle to separate the area with nodulizing material and is the part to be filled first in order to avoid premature master alloy dissolution. A covering material is also required, though generally in lesser quantities than used in the Sandwich process.

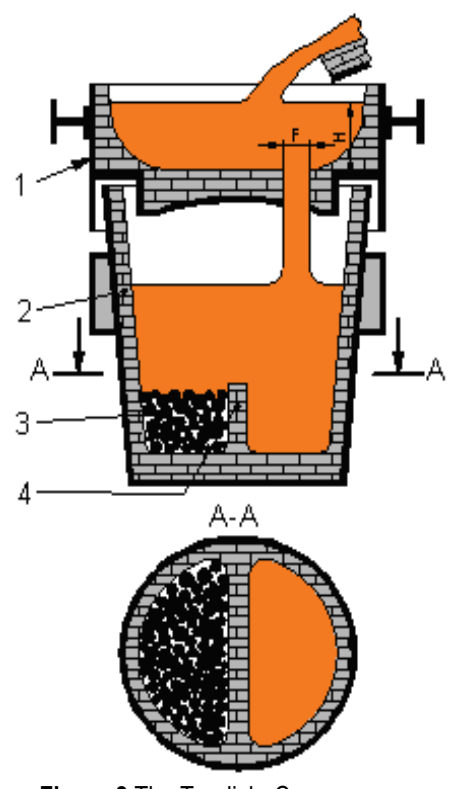

Figure 8 The Tundish-Cover process

The most difficult operation during the cast iron nodulizing with magnesium is introducing the nodulizing metal or its alloys to the melt $[1-6,12]$. This is caused by a large density difference between cast iron (about $7 \mathrm{~g} / \mathrm{cm}^{3}$ ) and magnesium (about $1.7 \mathrm{~g} / \mathrm{cm}^{3}$ ) that leads to floating of magnesium.

The foundries production capacity in ductile iron can determine the type of nodulizing treatment or type of nodulizer $[1-6,12]$. Nowadays, the treatment processes commonly used are those in the ladle, and those that use Fe$\mathrm{Si}-\mathrm{Mg}$ alloys as a nodulizer are applied in most of the foundries. 
Continuing developments in liquid metal treatment technologies have made major contributions to the quality, performance and reliability of metal castings. Advances in melt conditioning, in magnesium treatments to produce ductile irons, and in nodulizing techniques have ensured that cast irons remain key and competitive engineering materials.

\section{METHODOLOGY \& MATERIALS}

In order to modify these irons, developed in electric induction ovens (with chemical compositions according to [14]), classical nodulizing methods - the Open Ladle method, the plunging bell immersion (Plunging method), the Sandwich method, the Trigger method and one of the covered ladle methods, i.e. Tundish-Cover - were used (described above in Section 2).

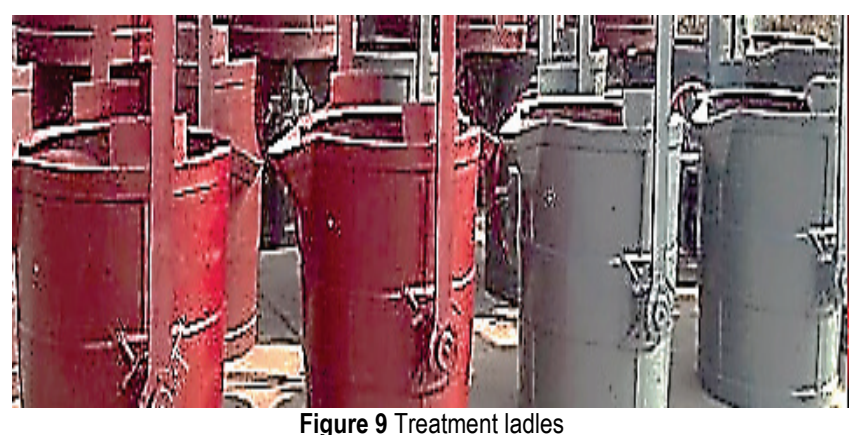

Table 1 Silicon based pre-alloys used in experiments [15]

\begin{tabular}{|l|c|c|c|c|c|c|}
\hline \multirow{2}{*}{$\begin{array}{c}\text { Silicon based } \\
\text { pre-alloys }\end{array}$} & \multicolumn{7}{|c|}{ Chemical composition (\%) } \\
\cline { 2 - 7 } & $\mathrm{Mg}$ & $\mathrm{Si}$ & $\mathrm{Ca}$ & $\mathrm{Al}$ & $\mathrm{Ce}$ & $\mathrm{Ba}$ \\
\hline FeSiMg 5 & 5 & 42 & 0.5 & 1.0 & 1.5 & 0.5 \\
\hline FeSiMg 6 & 6 & 42 & 0.5 & 1.0 & 1.2 & 0.5 \\
\hline FeSiMg 10 & 10 & 42 & 0.5 & 1.0 & 1.2 & 0.5 \\
\hline Nodulin 5.8 & 5.8 & 48 & 1.5 & 1.0 & 2.0 & 1.2 \\
\hline
\end{tabular}

(a)

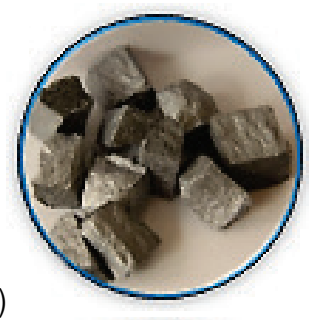

(c)
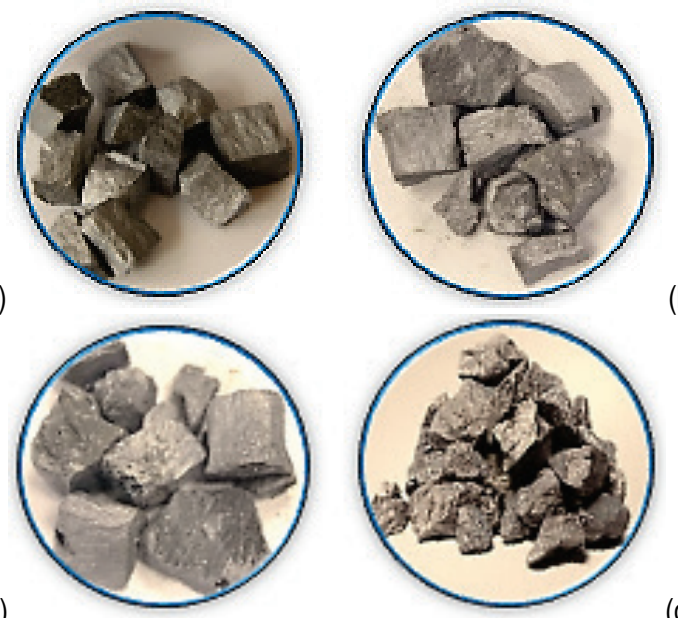

(b)

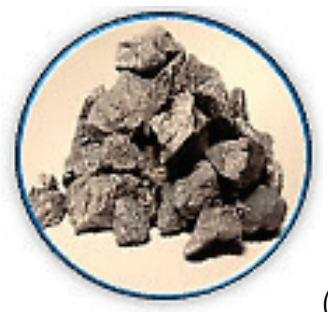

(d) (a) Fe-Si-Mg 5; (b) Fe-Si-Mg 6; (c) Fe-Si-Mg 10; (d) Nodulin 5.8

As nodulizers $\mathrm{Fe}-\mathrm{Si}-\mathrm{Mg}$ pre-alloys were used (Fig. 10), with different percentages of magnesium (i.e. 5, 6 and 10\%), but also a special magnesium-silicon based pre-alloy, considered "light pre-alloy", category Nodulin, with composition given by Tab. 1 (according to [15]).
Among the nodulizing agents that may be advantageously used in the process are magnesium, magnesium-ferrosilicon, cerium (Ce) containing magnesium-ferrosilicon, and rare earth oxides [1,2].

Under the practical conditions of nodulization process, in all our experiments, the same amount of iron, melted in an induction furnace (12.5 $\mathrm{t}$ ), using one of the above mentioned technique, with one of selected pre-alloy, has been treated.

The experiments starts from a given capacity of liquid iron $(1000 \mathrm{~kg})$, which has a temperature range of $1350-1450$ ${ }^{\circ} \mathrm{C}$. The amount of nodulizing alloy used is between 1.2 $1.8 \%$ of the quantity of treated iron, so that the remaining magnesium must be between 0.03 and $0.06 \%$. The pre-alloy are inserted in the ladle (granulation $20-40 \mathrm{~mm}$ ), preheated in advance, to increase the magnesium assimilation. The treatment effect lasts between 5-30 min, during which time the casting of iron must be carried out at $1400-1450{ }^{\circ} \mathrm{C}$.

\section{$4 \quad$ RESULTS \& DISCUSSIONS}

In a series of experiments on cast irons intended for the casting of rolling rolls, the classical Plunging, Open Ladle, Sandwich and Trigger techniques were incorporated, including the Tundish-Cover. A very important factor for the assessment of nodulization process is the degree of magnesium assimilation by the treated cast iron (called also the yield of magnesium). It is a proportion between the amount of magnesium remaining in the alloy and the total amount of magnesium introduced to the cast iron during its treatment. The direct data concerning the discussed parameter are presented in Tab. 2. Different degrees of assimilation of magnesium into the iron were obtained, depending on the method and the type of nodulizing prealloy used in the experiments. This data is rendered in a synthesized way in a summary table (Tab. 2).

\begin{tabular}{|c|c|c|c|c|}
\hline $\begin{array}{l}\text { Nodulizing } \\
\text { technique }\end{array}$ & $\begin{array}{l}\text { Nodulizing } \\
\text { agent } \\
(-)\end{array}$ & $\begin{array}{c}\text { Treatment } \\
\text { temperature } \\
\left({ }^{\circ} \mathrm{C}\right)\end{array}$ & $\begin{array}{c}\text { Quantity of } \\
\text { nodulizer } \\
(\%)\end{array}$ & $\begin{array}{c}\text { Degree of } \\
\text { magnesium } \\
\text { assimilation } \\
(\%)\end{array}$ \\
\hline \multirow{4}{*}{$\begin{array}{l}\text { Plunging } \\
\text { method }\end{array}$} & FeSiMg 5 & 1450 & 1.8 & 28 \\
\hline & FeSiMg 6 & 1450 & 1.8 & 29 \\
\hline & FeSiMg 10 & 1450 & 1.8 & 32 \\
\hline & Nodulin 5.8 & 1450 & 1.8 & 32 \\
\hline \multirow{4}{*}{$\begin{array}{l}\text { Open Ladle } \\
\text { method }\end{array}$} & FeSiMg 5 & 1450 & 1.8 & 33 \\
\hline & FeSiMg 6 & 1450 & 1.8 & 33 \\
\hline & FeSiMg 10 & 1450 & 1.8 & 33 \\
\hline & Nodulin 5.8 & 1450 & 1.8 & 34 \\
\hline \multirow{4}{*}{$\begin{array}{l}\text { Sandwich } \\
\text { method }\end{array}$} & FeSiMg 5 & 1450 & 1.8 & 35 \\
\hline & FeSiMg 6 & 1450 & 1.8 & 35 \\
\hline & FeSiMg 10 & 1450 & 1.8 & 36 \\
\hline & Nodulin 5.8 & 1450 & 1.8 & 38 \\
\hline \multirow{4}{*}{$\begin{array}{l}\text { Trigger } \\
\text { method }\end{array}$} & FeSiMg 5 & 1480 & 1.8 & 42 \\
\hline & FeSiMg 6 & 1480 & 1.8 & 43 \\
\hline & FeSiMg 10 & 1480 & 1.8 & 45 \\
\hline & Nodulin 5.8 & 1480 & 1.8 & 50 \\
\hline \multirow{4}{*}{$\begin{array}{l}\text { Tundish- } \\
\text { Cover } \\
\text { method }\end{array}$} & FeSiMg 5 & 1480 & 1.8 & 45 \\
\hline & FeSiMg 6 & 1480 & 1.8 & 47 \\
\hline & FeSiMg 10 & 1480 & 1.8 & 51 \\
\hline & Nodulin 5.8 & 1480 & 1.8 & 58 \\
\hline
\end{tabular}


Unlike gray iron, which contains graphite flakes, ductile iron has an as-cast structure containing graphite particles in the form of small, rounded, spheroidal nodules in a ductile metallic matrix. Treatment to produce ductile iron involves the addition of magnesium to change the form of the graphite, followed by or combined with nodulizing of a siliconcontaining material to ensure a graphitic structure with freedom from carbides. The research describes the in-ladle methods with silicon based magnesium pre-alloys treatment.

This study takes into account, the followings:

- The nodulizing agent (nodulizer), which indicates the optimal procedure when several categories of modifiers ( $\mathrm{Fe}-\mathrm{Si}-\mathrm{Mg}$ and Nodulin) are available;

- The magnesium content of each nodulizing agent, corresponding to the chosen procedure,

- The degree of assimilation of magnesium, which shows the performance of the chosen process, depending on both the modifier used and the temperature of the treatment, the size of the ladle, the composition of the cast iron to be treated, the amount of cast iron elaborated and necessary for nodulizing etc.;

- The cost of the investment, for the adoption of an optimal process. A simple nodulizing ladle shall be considered as a basis, plus the costs of adapting the technologies.

- The flexibility of the used technique, which describes the elasticity of the process, the freedom to modify the treatment process, by improvement or alternative to the existing one;

- The smoke emissions, which shows how polluting the process may be, due to magnesium evaporation or the reaction smoke. Thus, a separate ventilation system is required for high emissions, which also raises the cost of investment.

- The sulphur restrictions, showing the maximum recommended sulphur content, from the preparation, before treatment, sulphur being a factor dictating the applicability of one process or another;

- The risk of the silicon growth when the $\mathrm{Fe}-\mathrm{Si}-\mathrm{Mg}$ range is used as a nodulizer.

Based on the results obtained in the performed experiments, we can conclude the followings:

- The classical modification procedures (Plunging, Open Ladle, Sandwich / Over pouring and Trigger) provide relatively low degrees of assimilation of magnesium embedded in the pre-alloys. For the purposes of increasing assimilation, practice shows that the TundishCover process can be used at higher performance as alternatives to the classic techniques.

- The nodulizer's granulation $(20-40 \mathrm{~mm})$ was subject to the conditions of ensuring an optimal.

- A separate ventilation system is required for high emissions, which also raises the cost of investment. It should be noted that only one of the nodulizing technology (Tundish-Cover) complies with the severe environmental protection. The cover attached to the treatment ladle, considerably reduced the emission of smoke and flame, ensuring the protection of the foundry environment.
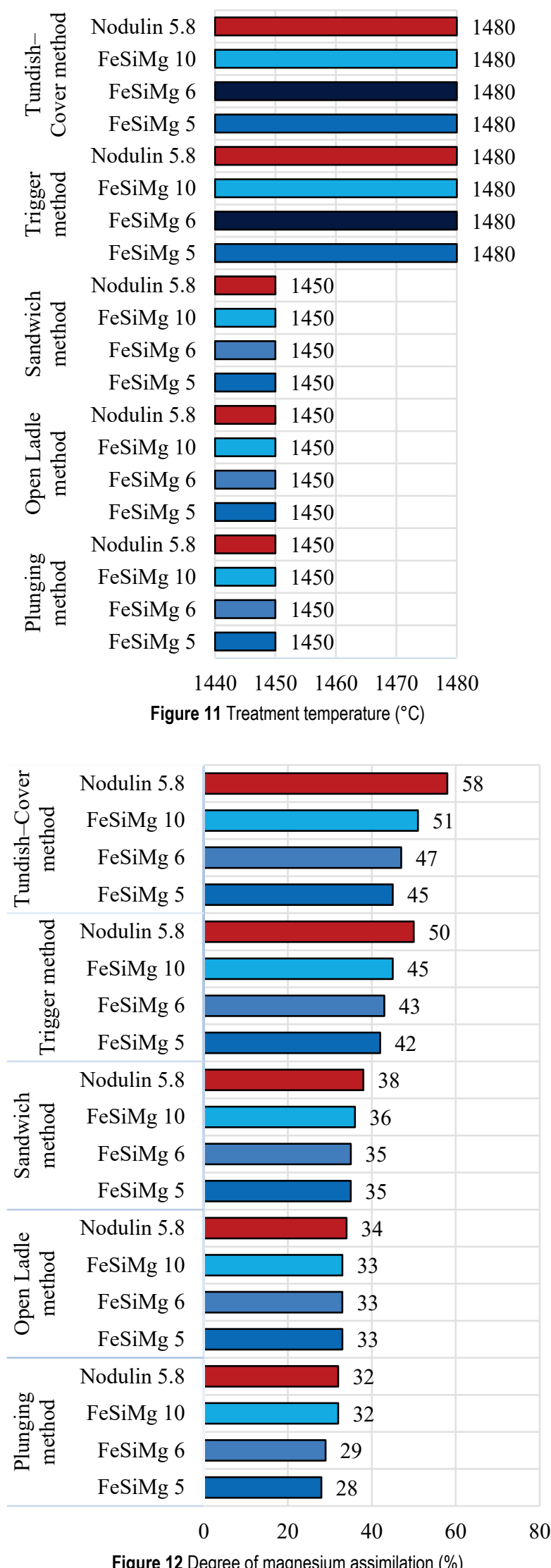

Figure 12 Degree of magnesium assimilation (\%) 
- There is a risk of silicon increasing in cast iron due to the nodulizing agent. In this respect, it was sought that the iron, in the melting phase, should contain minimum values prescribed by the standards.

- Most ladle treatment methods involve the use of magnesium-ferrosilicon alloys in specially prepared ladles as in the Sandwich and Tundish (covered ladle) processes. Compared to Open Ladle treatments, the use of a covered Tundish ladle gives better magnesium recovery with much less fume.

\section{CONCLUSIONS}

In the "in-ladle treatment method" the nodularizer alloy is placed in the bottom of the ladle whereafter liquid cast iron is filled into the ladle on the top of the nodularizer alloy. Depending on how the nodularizer alloy is placed in the ladle, the method is known as Open Ladle, Overpour / Sandwich, Trigger or Tundish-Cover treatment methods. These basic treatment methods are used in our experiments. Four different experiments were performed, for each method. In three of the experiments magnesium-ferrosilicon alloy with different magnesium content were used (5, 6 and 10\%), and for comparison purpose, one experiment was done with Nodulin 5.8, a special magnesium-silicon based pre-alloy.

From the multitude of alternatives presented, in the case of nodulizing process, foundries can make these constructions themselves, at quite low costs. Everyone can choose the system according to the facilities, possibilities and needs of this sector. It all comes down to choosing a process, which by practical application leads to the best efficiency of assimilation, as a primary and economic purpose, but also to reduce, as far as possible, the costs of production and last but not least, to reduce the emission of gas and smoke, in order to achieve a clean climate, in these sectors with a high degree of pollution.

Proper nodulizing process of irons cannot be over emphasized, because this technological step defines the final microstructure and resultant properties and minimizes problems. The nodulizing process, if done correctly, produces the correct mechanical properties, improves machinability, and will decrease shrinkage. Therefore, the magnesium treatment is an important step in ductile iron processing.

\section{REFERENCES}

[1] Riposan, I. \& Skaland, T. (2017). Modification and inoculation of cast iron. Stefanescu, D. M., Ed., Cast Iron Science and Technology Handbook. American Society of Materials: Cleveland, USA, 160-176. https://doi.org/10.31399/asm.hb.v01a.a0006315

[2] Ripoşan, I., Chişamera, M., Stan, S., Grasmo, G., Hartung, C., \& White, D. (2009). Iron quality control during melting in coreless induction furnace. AFS Transactions, 117, 423-434.

[3] Skaland, T. (2001). Inoculation material improves graphite formation in ductile iron. Modern casting, 91(12), 43-45.

[4] Skaland, T. (1999). Ductile iron production - A comparison of alternative treatment methods. Metal Asia, 7(1), 11-15.
[5] Skaland, T. (1997). Ductile iron production - A comparison of alternative treatment methods. Indian Foundry Journal, 43, $27-$ 37.

[6] Skaland, T. (1992). Production of ductile cast iron from high purity charge materials. Scandinavian Journal of Metallurgy, 21(2), 63-67.

[7] Zhang, W.-H., Ding, J., \& Nie, F.-R. (2009). Nodulizing alloy and treatment of iron melt. Foundry, 58(11), 1176-1180.

[8] Zhou, H.-L., Yu, H.-Y., Sun, Y.-X., \& Hu, J. (2013). Effect of nodulizer on chemical composition of ductile iron. Foundry Technology, 34(5), 584-586.

[9] Wang, C.-D., Sun, Y.-X., Li, M., \& Guo, Z.-T. (2004). A review of common nodulizing treatment processes. Modern Cast Iron, 24(3), 62-64.

[10] Guo, Z. T., Sun, Y. X., \& Li, M. (2006). Effect of Mg content in nodulizer on the absorptivity of Mg. Foundry, 55(6), 623625.

[11] Lerner, Y. S. \& Panteleev, G. V. (2003). Magnesium treatments in ductile iron production - Part 2. Foundry Management and Technology, 131(2), 24-29.

[12] Olawale, J. O., Ibitoye, S. A., \& Oluwasegun, K. M. (2016). Processing techniques and productions of ductile iron: A review. International Journal of Scientific \& Engineering Research, 7(9), 397-423.

[13] Kiss, I. \& Hepuţ, T. (2002). The hardness of the cast iron rolls, assured by the alloy elements and the modification treatment of the graphite nodularity. Scientific Bulletin of the University Politehnica Timişoara, Transactions on Mechanics, 47(2), 169-174.

[14] STAS 9432-85: Rolling mills. Half-hard cast iron rolls specification. (in Romanian)

[15] STAS 11240-88: Nodulizing pre-alloys for cast iron. (in Romanian)

\author{
Authors' contacts: \\ Imre Kiss, PhD, Associate Professor \\ Politehnica University Timisoara, \\ Faculty of Engineering Hunedoara, \\ Department of Engineering and Management, \\ 5, Revolutiei, 331128 - Hunedoara, Romania \\ E-mail: imre.kiss@fih.upt.ro
}

